2021-01-10

\title{
Manufacturing and development of a bolted GFRP flange joint for oil and gas applications
}

\author{
Aljuboury, M \\ http://hdl.handle.net/10026.1/17446
}

\section{$10.1177 / 0954405421989517$}

Proceedings of the Institution of Mechanical Engineers, Part B: Journal of Engineering Manufacture

SAGE Publications

All content in PEARL is protected by copyright law. Author manuscripts are made available in accordance with publisher policies. Please cite only the published version using the details provided on the item record or document. In the absence of an open licence (e.g. Creative Commons), permissions for further reuse of content should be sought from the publisher or author. 
This is the authors' version of the paper published in Proc IMechE Part B: J Engineering Manufacture 1-11, () IMechE 2021, Article reuse guidelines: sagepub.com/journals permissions; DOI: 10.1177/0954405421989517; journals.sagepub.com/home/pib

\title{
Manufacturing development of a bolted GFRP flange joints for oil and gas applications
}

\author{
Muhsin Aljuboury ${ }^{1,2}$, Md Jahir Rizvi², Stephen Grove ${ }^{2}$, Richard Cullen ${ }^{2}$ \\ ${ }^{1}$ School of Civil Engineering, Al-Qalam University College, Kirkuk, Iraq \\ ${ }^{2}$ School of Engineering, Plymouth University, Plymouth, UK \\ Corresponding author: \\ Email: muhsin.aljuboury@plymouth.ac.uk \\ muhsin.aljuboury@alqalam.edu.iq \\ Phone: +964 7705169648
}

\begin{abstract}
The goal of this experimental study is to manufacture a bolted GFRP flange connection for composite pipes with high strength and performance. A mould was designed and manufactured, which ensures the quality of the composite materials and controls its surface grade. Based on the ASME Boiler and Pressure Vessel Code, Section X, this GFRP flange was fabricated using biaxial glass fibre braid and polyester resin in a vacuum infusion process. In addition, many experiments were carried out using another mould made of glass to solve the faced issues and obtain a bolted GFRP flange with high quality and characteristics. Moreover, a comparison investigation was conducted of drilling GFRP flange using two types of tools; Erbauer diamond tile drill bit and Brad \& Spur K10 drill. Several GFRP flanges (6) were manufactured to reach the final product with acceptable quality and performance. The flange was bonded to a composites pipe by using adhesive bonding method after chamfering the end of the pipe. Another type of composite flange, which is already available in the markets, was used to closed the other end of the pipe. Finally, blind flanges were used to closed both ends and making the pressure vessel, that will be tested under the range of the bolt load and internal pressure.
\end{abstract}

Keywords: Bolted flange joint, Composite flange, Glass fibre reinforced polymer, Vacuum infusion process, Piping. 


\section{Introduction}

Bolted flange joints made of fibre reinforced plastic (FRP) are widely used in many industries such as oil, gas chemical, petrochemical, power plants and offshore industries. This is because the systems in these industries usually include pumps, valves and other fittings that require periodic removal for maintenance. Fibre reinforced composites are preferred due to their unique combination of properties which includes high strength and modulus to weight ratios and high corrosion resistance $[1,2]$. For instance, the weight of a 12 inch diameter pressurized fuel line for carrying liquid hydrogen in a space shuttle was reduced by $20 \%$ when it was manufactured from composite materials [3]. Furthermore, FRP materials have a long life expectancy and low installation and maintenance costs [4]. Another important advantage of FRP is that designers have the ability to vary the material properties for a specific application. For example, high resin content provides maximum corrosion resistance; high glass content provides maximum physical strength. Therefore, designers can combine these two elements to produce a reliable design. Similarly, designers can also vary the mechanical properties by changing the directions of the fibres to resist a specific load in a specific direction. Moreover, the use of composite flanges to connect composite pipe helps to avoid the mismatches during thermal expansions of metal connecting pieces and composite pipes [5].

In terms of the literature review, only a very few studies have focused on the manufacturing of the composite flange joints. Tao et al. [5] studied a comparison of the connection between composite poles and composite flanges instead of metal flanges manufactured by aviation aluminium alloy in stratosphere truss structure. The used a Toray T700S-12K carbon fibre in three-dimensional full five directional braiding technology and tri-functioned epoxy resin TDE - 85\# through RTM (resin transfer moulding) process to manufacture the flange. The results show that the joint of carbon fibre poles with the carbon fibre reinforced polymer bolted flange performed better than the metal flange under the same operating conditions. Whitfield et al. [6] conducted experimental and numerical investigation for creep and unsymmetrical shrinkage during the post-cure of GFRP flange. The flange was fabricated by using hand lay-up method with a steel mould. The used raw materials are chopped strand mat fibre and Derakane Momentum 411-350 Vinylester resin. Many strain gauges were embedded between the layers and on the outer surfaces. From the investigations, they have observed that the correlations between spring back results are poor but for strain, results are good. The authors mentioned two possible reasons, firstly, various cure profiles were applied 
at various stages of lamination process and secondly, due to the thermal stress related creep in the resin at the elevated temperature during post-cure.

Kurz [7] carried out experimental, numerical and analytical investigations on the design of floating type bolted flange connections (Loose flange) made of GFRP materials capable of working at temperatures up to $80{ }^{\circ} \mathrm{C}$ in chemical industries. They used various types of gaskets made of rubber (EPDM) and polytetrafluoroethylene (PTFE) to check the gaskets performances with GFRP bolted flange at the elevated temperature. It is found that both the PTFE-gasket and PTFE-gasket with diffusion barrier perform better than EPDM-gaskets. The bolt-force decreased with heating up to $80{ }^{\circ} \mathrm{C}$ and bending occurred at the top surface of the flange. The results of analytical, experimental and FEA simulations all have shown good agreements with each other. Fangueiro [8] conducted experimental investigations on the development of FRP T-pipe joint. 3D weft-knitted fleecy fabrics with different structures such as fleece yarn linear, average ground yarn and average fleece yarn were tested to improve the mechanical properties. Glass fibre, polyester resin and RTM process were used with to fabricate the connection. The results show that the sample PA Glass 544 Tex exhibit the best performance to manufacture the T-connection with $43 \%$ fibre mass fraction and this is close to the desired value of $40 \%$.

In the present work, an experimental investigation was conducted to manufacture glass fibre reinforced plastic (GFRP) bolted flange by using glass fibre braid, polyester resin and vacuum infusion process. This particular type of fabric was chosen in this study because of its continuity over the entire flange body. Therefore, it is anticipated that the failure that usually occurs at the flange-hub intersections due to the discontinuity of fibres in this region will be minimised. In addition, a number of experiments were conducted to improve the method of flange fabrication thus to obtain a composite flange with high quality and performance.

\section{Designing the mould}

Designing the mould is one of the important factors that has significant effects on the manufacturing of composite flange using vacuum infusion process. Therefore, designing and manufacturing the mould with high quality not only determines the inherent quality of the composite material, but also controls the surface grade of the composite. Furthermore, appropriate mould plays a significant role in maximising the properties of the composite material that are greatly affected by fabricating process. In this study, the mould was designed and manufactured with mainly two parts to facilitate the flange removal from the 
mould after the curing. These parts are the mandrel and the plate, as well as the O-ring gasket and the bolts.

\subsection{Mandrel}

The mandrel was made of aluminium rod with 7" diameter. Aluminium alloy material (6082 T6) was chosen due to its sufficient strength and dimensional stability to withstand the bag pressure loads and compressive load during the forming and curing cycles. To achieve the required dimensions, the rod is machined and tapered from one edge as shown in Fig. 1. The purpose of this taper, which is equal to $1.75^{\circ}$, is to achieve the requirements of the taper-taper joint between the flange and the pipe and also to facilitate the removal of the flange from the mould and to avoid the stacking problem or damage to the flange. The external surface of the mandrel that is in contact with composite is subjected to surface finishing process to remove all asperities that increase the chance of the flange mould stacking and also to obtain a flange with good internal surface. This will improve the bonding strength between the flange and the pipe. In addition, the tapered end face of the mandrel was machined to create a groove for the O-ring rubber gasket (3.53 mm of cross-sectional diameter) and four holes with threads were created for inserting the bolts during assembly.

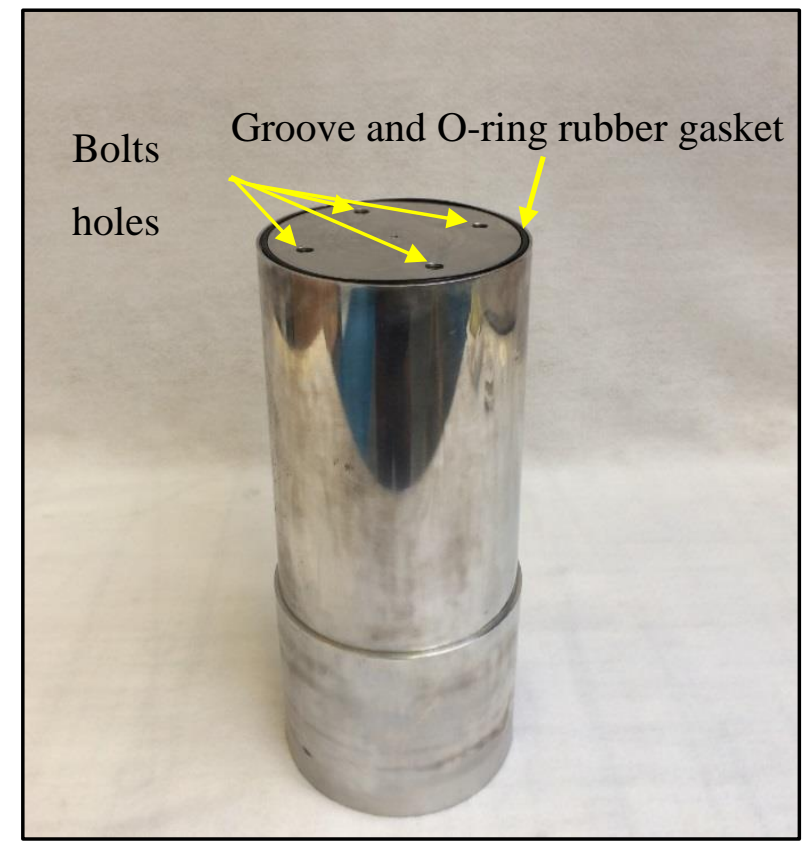

Fig. 1: The mandrel

\subsection{Plate}

The second main part of the mould is the plate, which is placed at the bottom and in direct contact with the lower flange face. Therefore, it requires a good surface finishing to avoid stacking over this area. Initially, the plate was made of aluminium alloy (6082 T6) with 
dimensions $650 \mathrm{~mm} \times 650 \mathrm{~mm} \times 10 \mathrm{~mm}$ and 4 holes were drilled around the centre of the plate for the assembly purposes. During the infusion process, the resin flow was found as problematic and this will be discussed in details later. This led to change the aluminium plate by another one that was made of glass. See Fig. 2. The reason of choosing glass material is to observe the resin flow during the infusion process and find the best input and output positions for the resin.

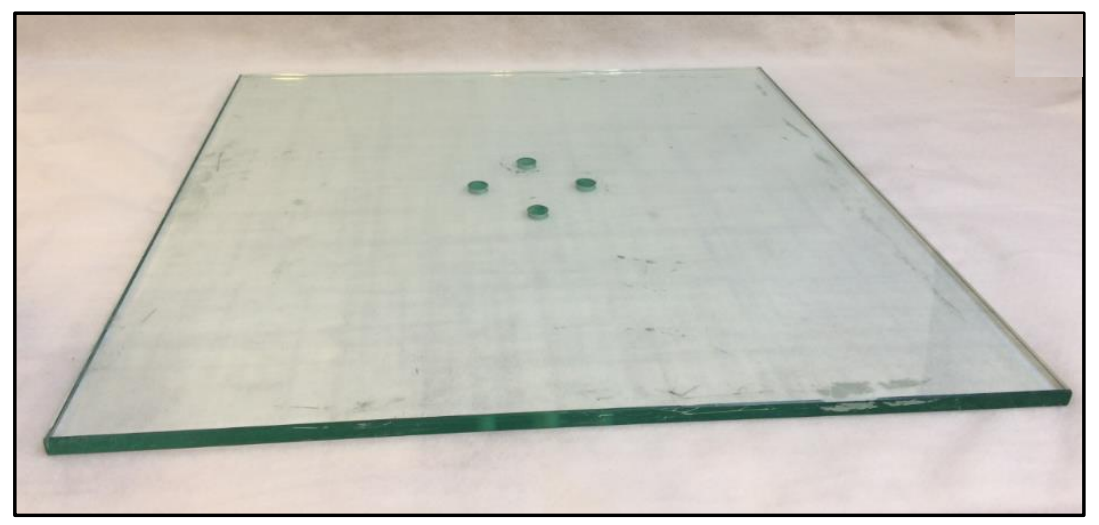

Fig. 2: The glass plate

\subsection{The mould assembly}

As showing in the Fig. 3, the parts of the mould were assembled by using four bolts of size M10 as well as O-ring rubber gasket. These bolts pass through the plate holes and are fastened to the identical holes that were drilled in the taper end face of the mandrel by using a thread tool. Before the assembly, the gasket was fitted in the groove. The purpose of using this gasket is to prohibit the leakage through holes of the bolts during the vacuum and to prevent the resin from reaching the contact area between the mandrel and the plate during the infusion.

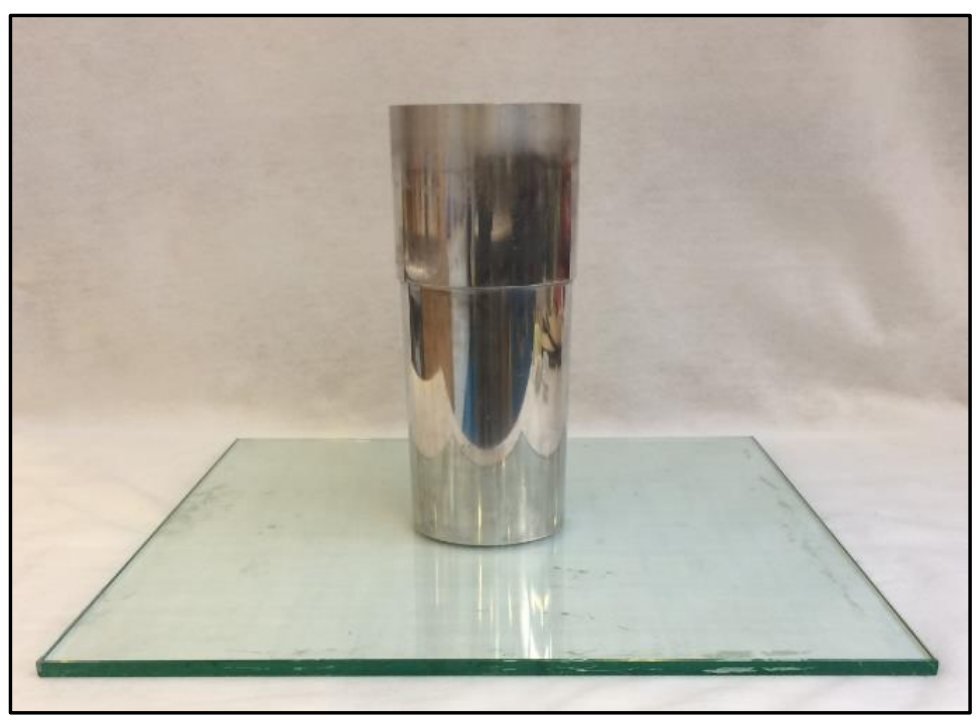

Fig. 3: The Mould of the composite flange 


\section{GRP Flange fabrication}

The geometry of the flange and the dimensions were chosen based on the ASME boiler and pressure vessel code, Section X [9] when the internal pressure is 3.4 bar. The vacuum infusion process (bag moulding) was chosen to manufacture the composite flange of 6-inch nominal diameter. This manufacturing method was selected due to its' flexibility for manufacturing composite with complex geometry. It's cheap and it provides good strength compare with other methods such as hand layup or RTM, which also require close system mould. Fig. 4 illustrates a schematic of manufacturing GFRP flange by using a vacuum infusion process. This manufacturing process has included a number of steps which are described briefly as follows:

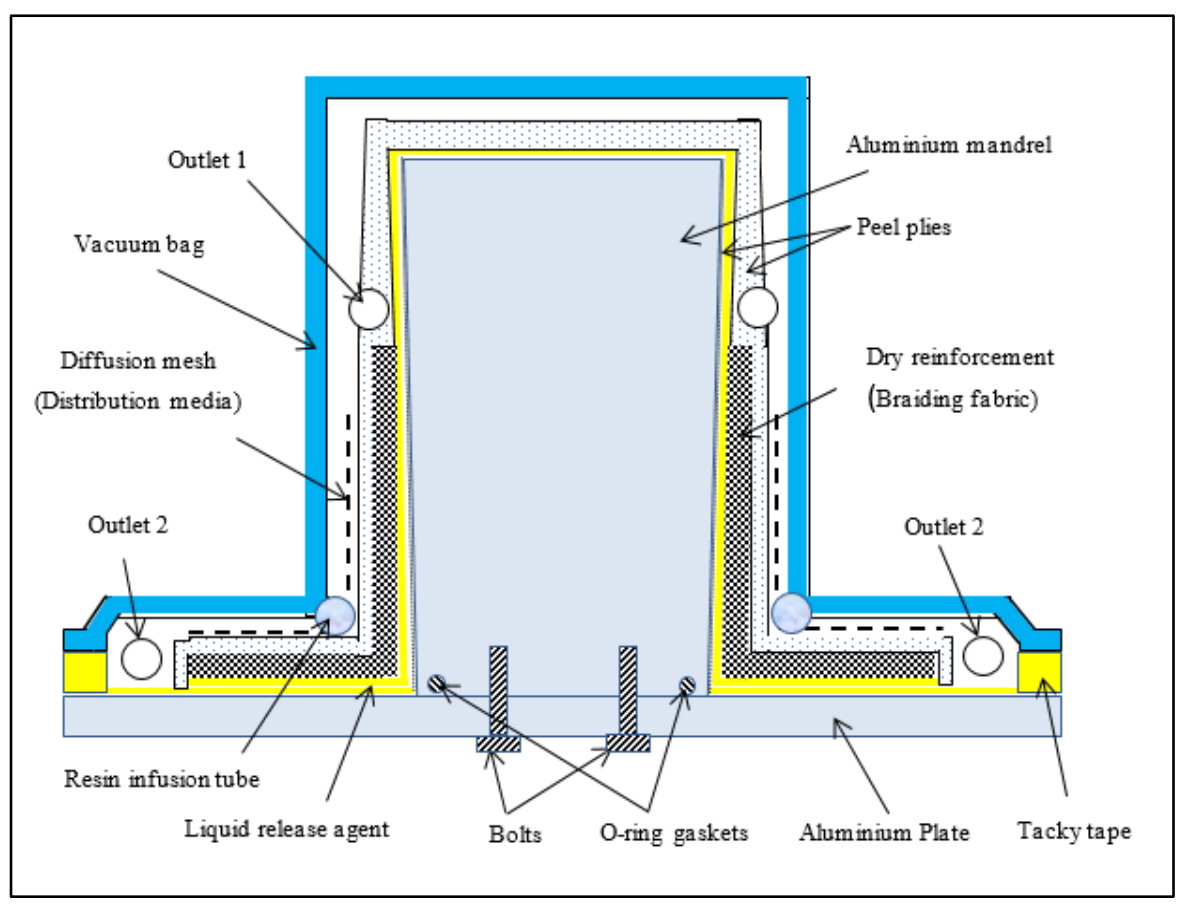

Fig. 4: Schematic diagram of the vacuum infusion process

1. Peel ply: after coating the outer surfaces of the mould that are in contact with the composite flange by a released agent (FREKOTE 770-NC PT CN), the peel ply is used in two instances. At the first instance, it is used to cover the surface of the mould, which is in contact with the flange before putting the fabric. This helps the trapped air bubbles between the fabric and the mould to leave during the vacuum and the resin infusion, thereby, reducing the voids or porosities and improving the mechanical properties of the composite flange. The other purpose of using the first peel ply is to 
leave an imprint or pattern on the flange surface to enhance adhesive bonding between the flange and the pipe. In addition, to increase the coefficient of friction between the rubber gasket and the flange face and preventing the pushing out of the gasket during the operating condition.

For the second instance, it is used between the fabric and the diffusion mesh as well as the bag to prevent them from sticking to the composite flange after the curing action and to improve the outer surface finish of the flange.

2. Fabric layup: braid fibreglass was chosen to fabricate the composite flange in this study. This type of the fabric was chosen due to its continuity from the hub to the flange around the entire flange (flange neck) and the continuity in the radial and hoop directions, which minimize the flange rotation under the uneven distribution of the bolt loads. In addition, this will reduce the bending moment, thereby reducing the flange rotation that encourages the leakage propagation. A number of previous studies $[10,11]$ have indicated that the most common types of failures in commercially available GRP flanges manufactured by hand lay-up or filament winding processes occur at the flange-hub intersections, due to the discontinuity of fibres in this region. See Fig. 5. The layers of the braid fibreglass sleeves are laid up over the mandrel and expanded out over the plate more than the required diameter of the flange as shown in Fig. 6. This process is repeated many times until the required thickness is achieved.

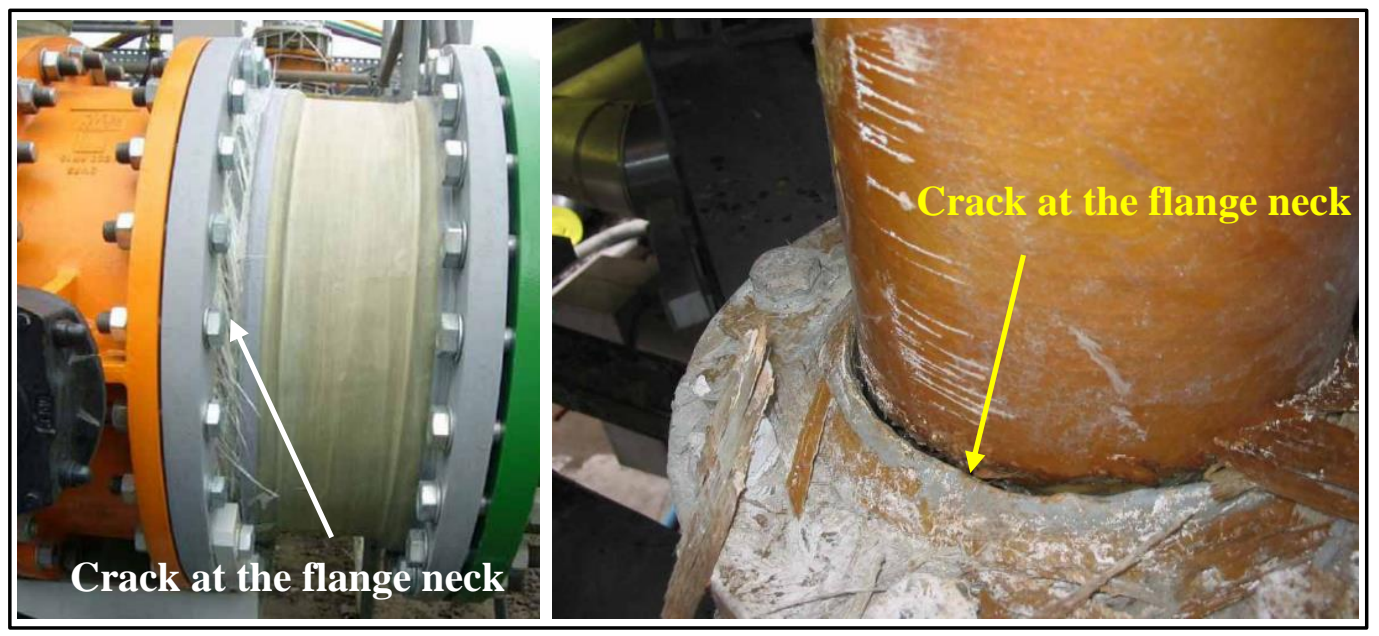

Fig. 5: Common failure on the GFRP flanges [10] 


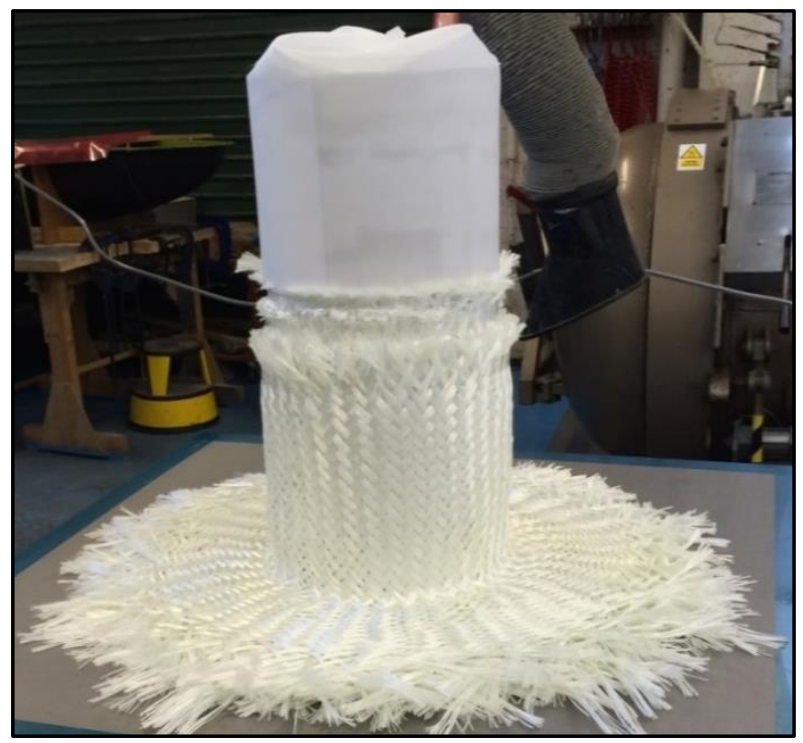

Fig. 6: Laid braided fiberglass fabric on the mandrel and the plate

3. Vacuum infusion process: after putting the diffusion mesh as shown in the Fig. 7, a flexible bag is used to cover all the components. The edges of the bag are stacked on the edges of the plate to close the system as shown in the Fig. 8. Meanwhile, the outlets of the infusion process were kept fixed at the top and along the outer diameter of the flange. After that, a vacuum is applied and the polyester resin, which is mixed with $1 \%$ of a catalyst, is infused through the inlet of the system.

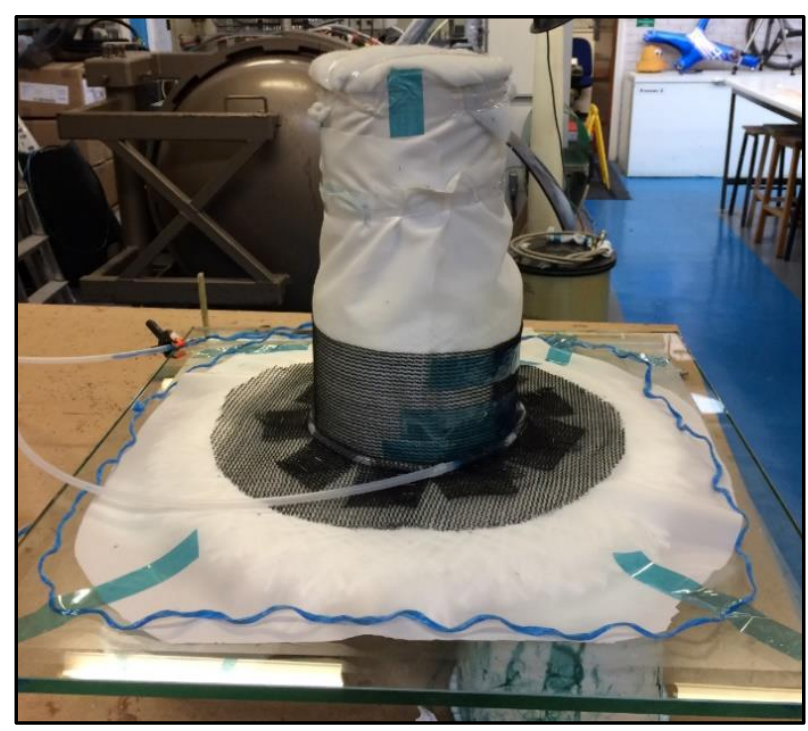

Fig. 7: Diffusion mesh distribution

In addition, the vacuum process is continued until the flange is completely cured at the room temperature. After the curing, the vacuum process is stopped, vacuum bag, diffusion mesh, and peel ply all are stripped off and the flange is removed from the mould. 


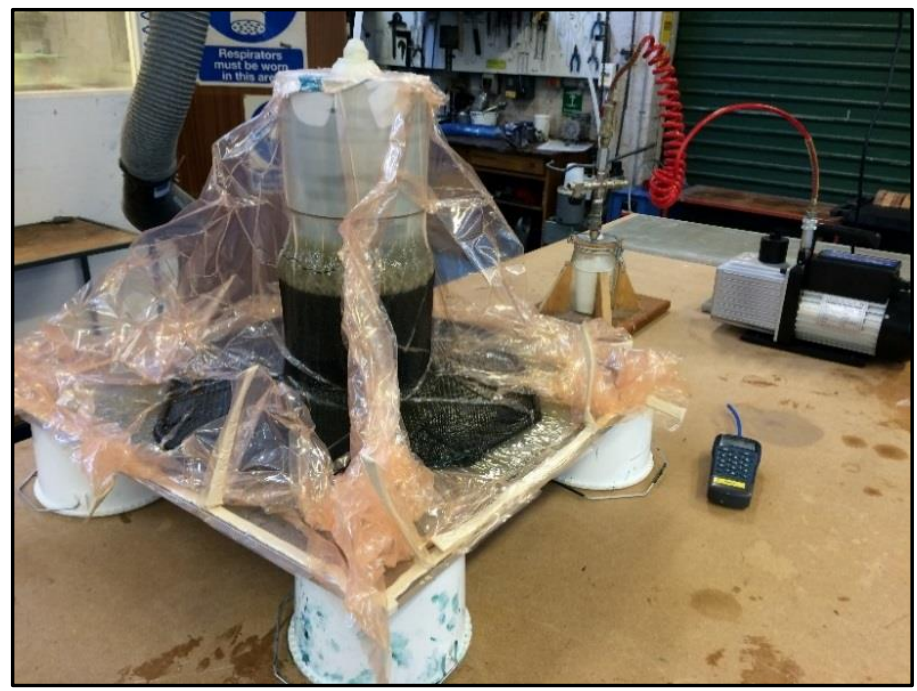

Fig. 8: Bagging and resin infusion process

4. Flange machining: as the wastage of the braiding at the edges cannot be avoided, initially the braiding fabric was kept larger than the required physical dimensions of the flange and finally was shortened by cutting off the unwanted regions of the manufactured flange as can be seen in Fig. 9. The composite flange was cut using two cutting machines. For the flange disc, a jig saw was used whereas for the flange hub, a disc cutter was used. After the cutting, a sand paper was used to make the edges are smooth.

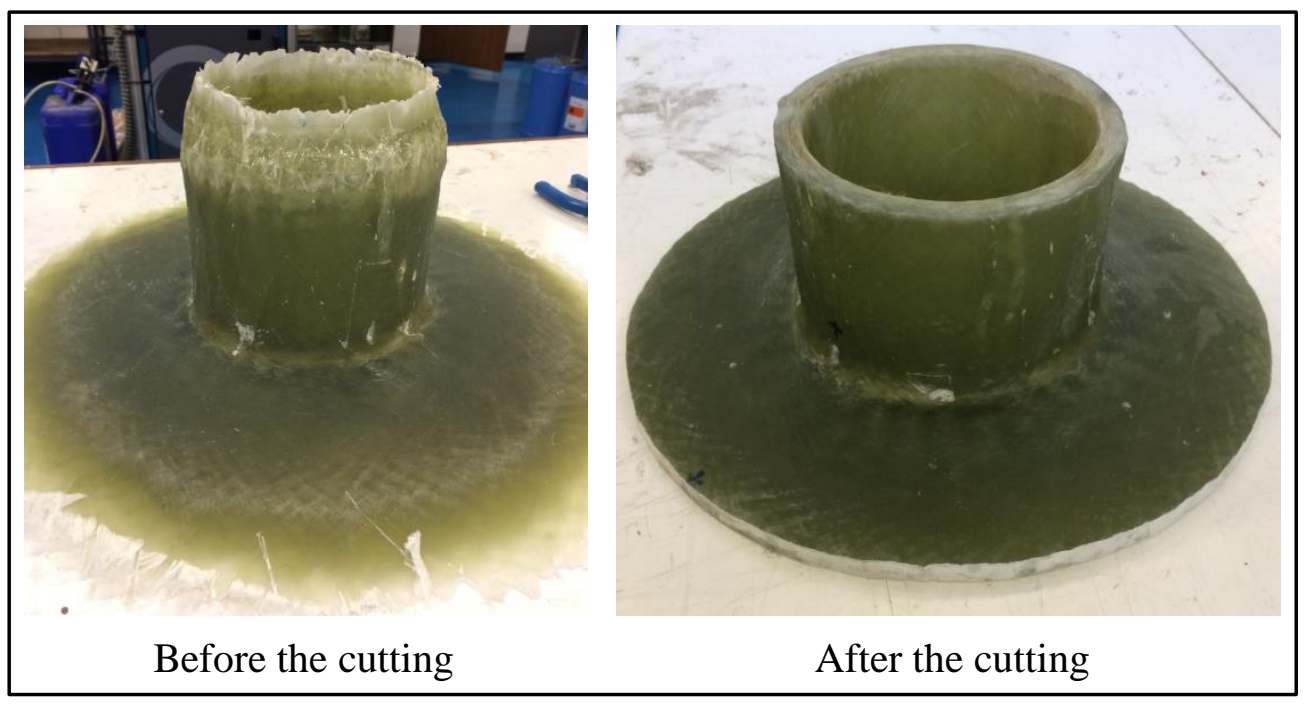

Fig. 9: Machining of the composite flange 


\section{Issues with the manufacturing process}

During the manufacturing of the GFRP flange, two issues were identified: (1) inadequate resin flow and (2) voids and cracks at the flange neck. Details of these issues are discussed below.

\subsection{Resin flow problem}

The main issue that was faced during the GFRP flange fabrication process is the inadequate resin flow. This has led to have dry regions around the diameter of the bolts holes circle and at the lower face as illustrated in Fig. 10. Initially, the inlet of the resin was placed at the outer diameter or edge of the flange disc while the outlet was fixed on the top as shown in the Model A of Fig. 14. The first flow flows through the diffusion mesh at the top surface of the flange from the resin inlet, which was allocated at the flange edge, toward the centre. Some of this resin pass through the thickness (fabric) at the flange-hub intersection due to the sudden changing in the geometry and started to flow in the opposite direction (reverse flow) toward the outer diameter at the bottom face of the flange. The second flow flows from the inlet toward the centre at the bottom face of the flange. At some points, these flows met and trapped air at the meeting regions. Thus, the resin doesn't fill the meeting regions properly and leads to have dry regions, which are illustrated in the Fig 10.

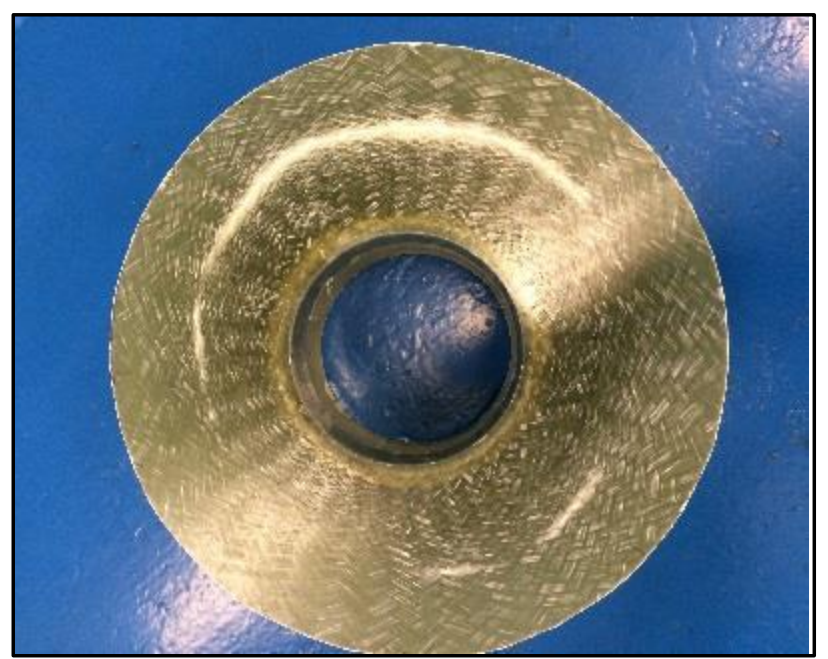

Fig. 10: Flange with dry regions on the face

\subsection{Voids and cracks problem}

After curing the composite flange, it was cut into many pieces for a number of purposes such as performing mechanical tests, measuring the fibre volume fracture (VF) and capturing optical microscopy images. In order to investigate the voids and the cracks, many samples were taken from the flange-hub region (flange neck), which represents the critical point in the 
flange. Fig. 11 shows an image of the flange neck region. It can be seen that many voids and cracks occur at this region when the inlet of the infusion was in the flange edge and the outlet was in the top of the flange. This case is named as Model A, which will be discussed elaborately later. In addition, most of the voids and cracks were found close to the upper face of the flange. This occurs due to the resin shrinkage and exothermal behaviours at the flange neck. As this region connects the flange and the hub, it experiences the most effects of the flange shrinkage. Also, it is the thickest part in the flange, thus high temperature is produced due to exothermal reaction.

The reason of concentrating the voids and the cracks at the upper half of the flange is that the lower surface and the internal faces of the flange are bigger than the upper face and they have direct contacts with the mould, which is made of aluminium and glass. The mould helps to cool the composite by transferring the heat through it to the environment. In contrast, the upper face of the flange-hub intersection area is less and covered by the peel ply and the vacuum bag, which are inhibiting the heat transfer. Therefore, the amount of the transferred heat from the lower and the internal faces of the flange is more than that from the upper face. As a result, most of the voids and the cracks were formed at the upper half of the composite instead of the lower half. These voids and cracks represent weak points in the flange body and the stresses concentrate around them. In addition, they occurred at a critical region of the flange, which is the flange neck. Most of the failures in the current commercial composite flanges occur at this region. This region is usually subjected to high bending moment due the applied bolt load and internal pressure. Therefore, the voids and crack should be minimized as much as possible to avoid any possible failure in this area.

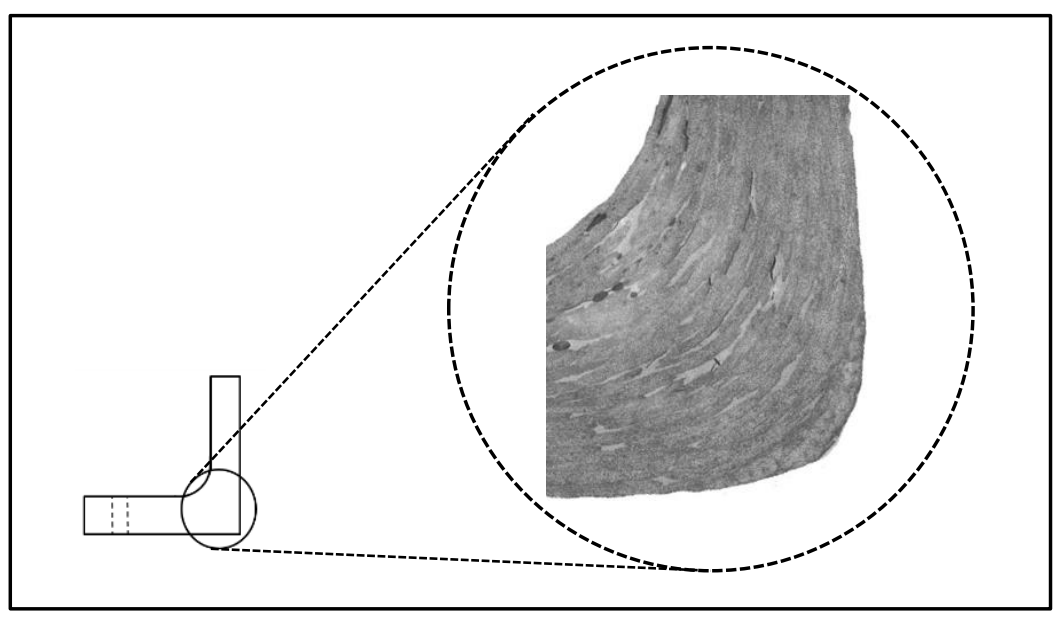

Fig. 11: Microscopy image for the flange-hub intersection 


\section{Solving the issues}

To solve or minimize the issues faced during manufacturing the GFRP flange, two investigations were carried out. The first investigation, which involves substantial number of experiments studies the effect of the inlet and the outlet positions of the resin on the formation of the dry areas, voids and cracks. The other investigation is conducted by changing the infusion temperature to study its influence on the viscosity of the resin.

\subsection{Resin inlet and outlet positions effect on the resin flow}

Changing the inlet and the outlet positions of the resin in the vacuum infusion process is one of the important parameter that has significant effect on the flange strength and especially on the faced issues, i.e. dry region, voids and cracks. To investigate the effect of this changing on the faced issues, another mould was manufactured by using glass material as shown in the Fig. 12. This material is clear and allows to see all the resin flow through the mould at any region during the infusion process. In addition, in each experiment, a portion of the flange was fabricated using the same fabric, resin and manufacturing process as illustrated in Fig. 13.

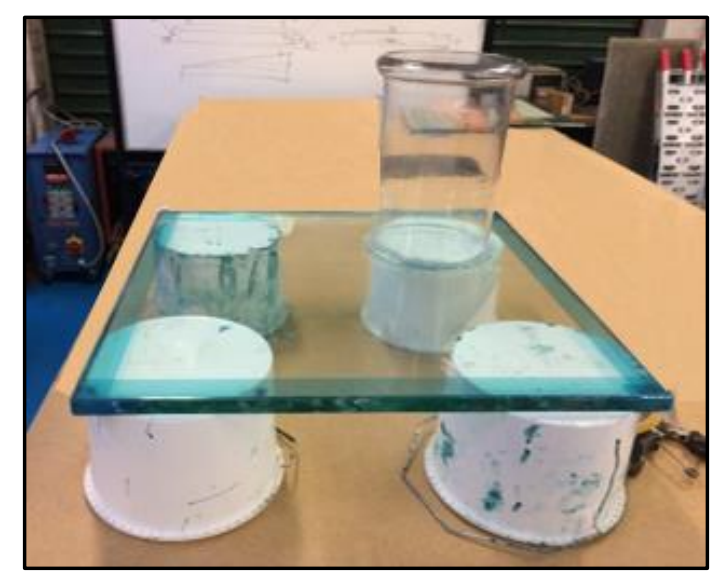

Fig. 12: Glass mould of the experiments

Three experiments with different inlet and outlet positions of the resin were carried out. These experiments were called Model A, Model B and Model C as shown in Fig. 14. Model A has the inlet at the outer diameter of the flange (flange edge) and the outlet in the top of the flange. Model B has the inlet at the top of the flange and the outlet at the flange disc edge. The third one is model $\mathrm{C}$ that includs the inlet at the flange neck and two outlets-one at the flnage disc edge and the other at the top of the flange hub. During the infusion, the resin flow was vedioed for each experiment and studied. The results showed that the model $\mathrm{C}$ has achieved the best resin flow and also quicker than the other models. This helps to distribute the resin over all the flange body within a short time and avoid any dry fabric which occurred with the model A. (See Fig. 15). 


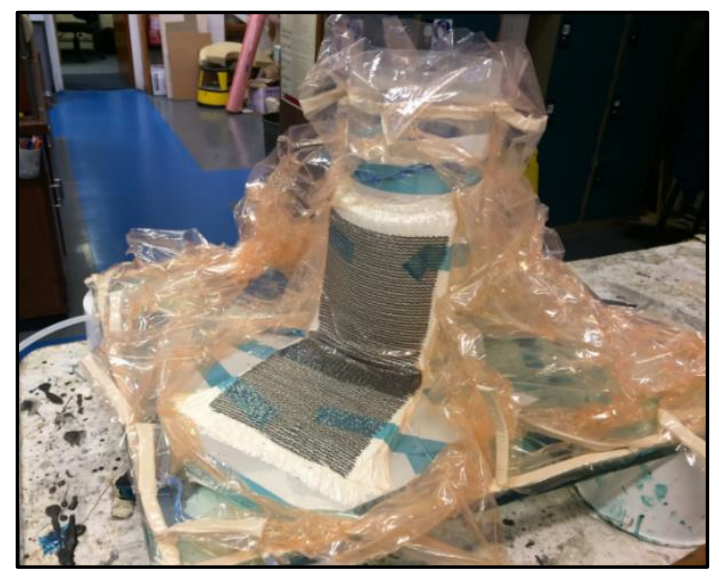

Fig. 13: The vacuum infusion process of the experiments

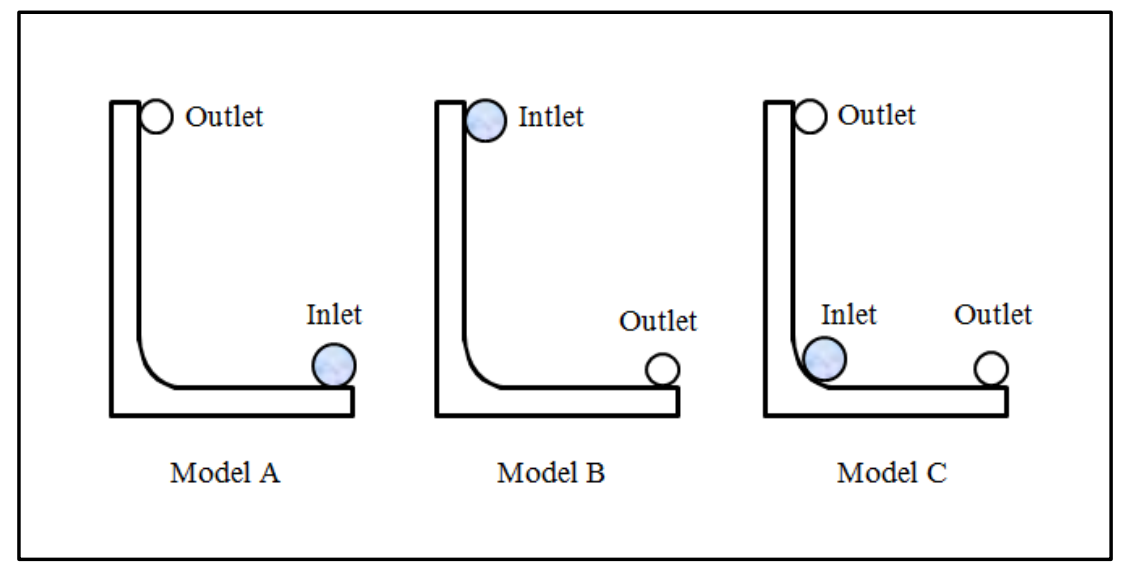

Fig. 14: Inlet \& outlet positions of the conducted experiments

In addition, a sample was taken from the flange neck (flange-hub intersection) for each experiment to study the voids and the cracks under the microscope. Then, the voids and the cracks percentages were also calculated by using Image $\mathbf{J}$ software for each smaple. The obtical microscope images of the samples and the percentage of the voids and cracks are shown in Fig. 16. The obtained results showed that the voids and the crack precentages reduced siginificantly with the Model C (4.3\% for Model A, $4.24 \%$ for Model B and $1.58 \%$ for Model C). This was taken into account to choose Model $\mathrm{C}$ for manufacturing the final form of the composite flange. 


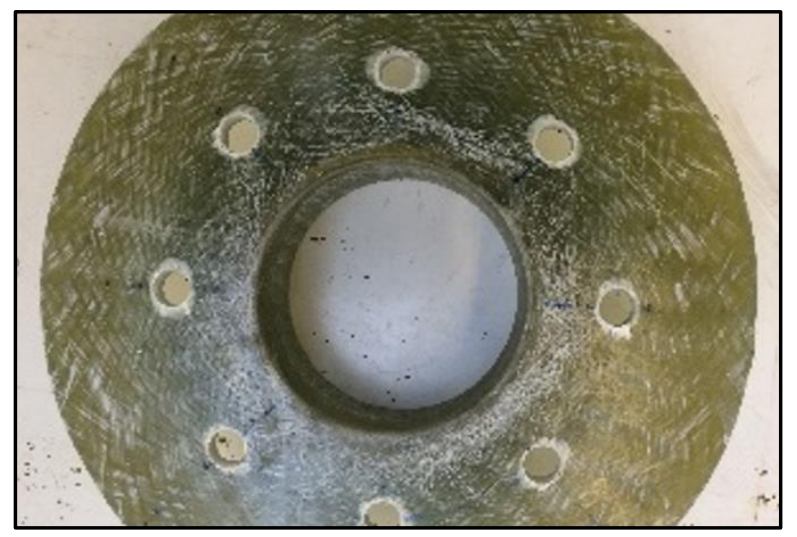

Fig. 15: Flange without dry fabric on the face

Furthermore, the temperatures at the flange-hub intersection and through the thickness were monitored for the Model $\mathrm{C}$ during the infusion and throughout the curing. This is done by embedding a thermocouple through the composite layers at the aforementioned position, which is illustrated in the Fig. 17. This region was chosen because it is the thickest and expected hottest part in the flange body due to small surface area, which limits the heat transfer.

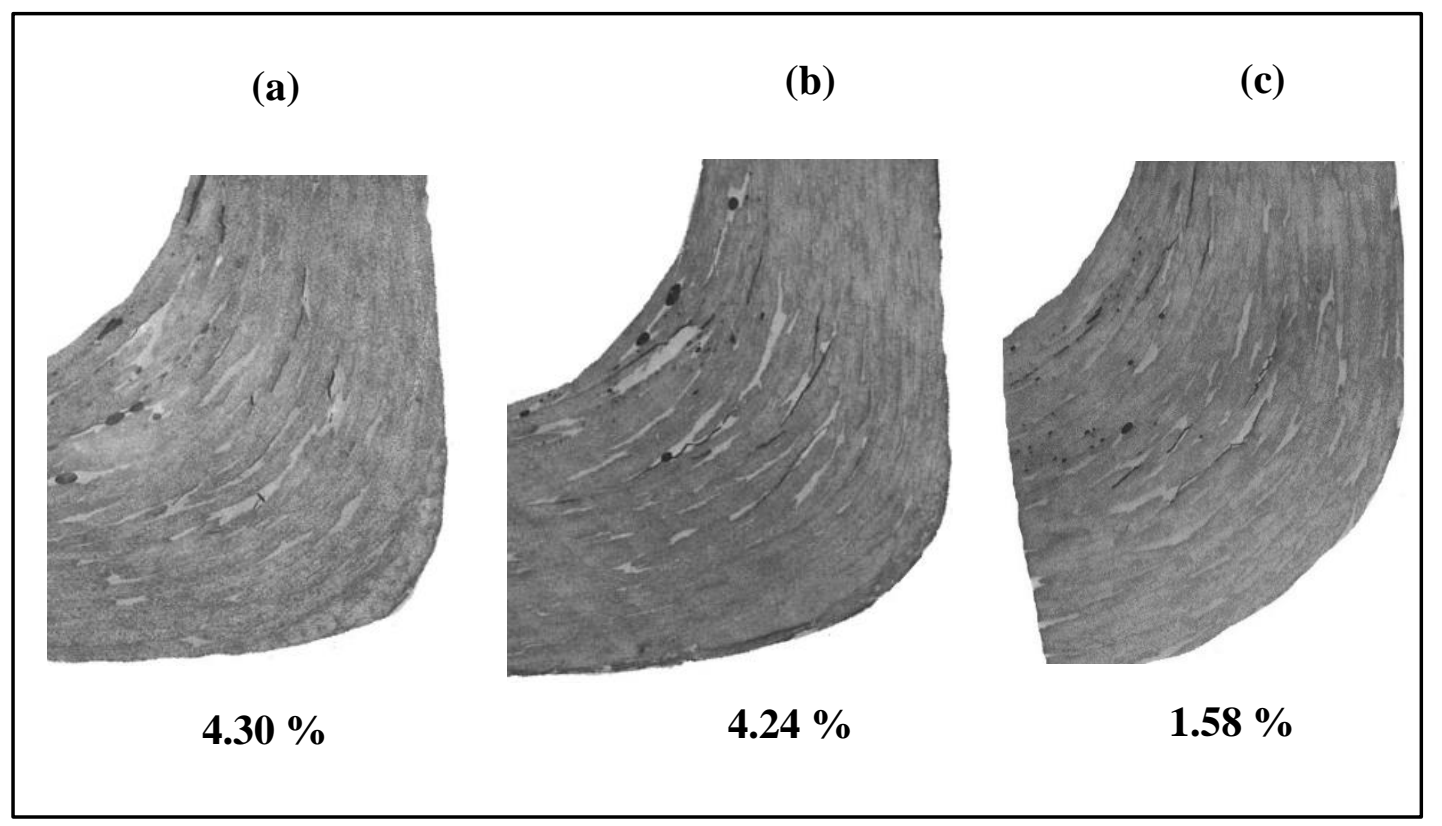

Fig. 16: Microscope images at the flange-hub intersection (a) model A, (b) model B, (c) model C.

The variation of the temperature with time was shown in the Fig. 18. The results showed that the temperature has increased during the first three hours but decreased later. The room temperature was $18.3^{\circ} \mathrm{C}$. The maximum temperature was $31.2^{\circ} \mathrm{C}$ after three hours from the starting time. This is because of the exothermal reaction during the infusion and curing of the 
resin. However, the variation range was not high enough in this model (C) and that was because of the position of the inlet resin infusion. This helps to cool this part by transferring the heat from this part to the others through the resin, which flow through this region. This in turn helped to reduce the voids and cracks in this part for the model C.

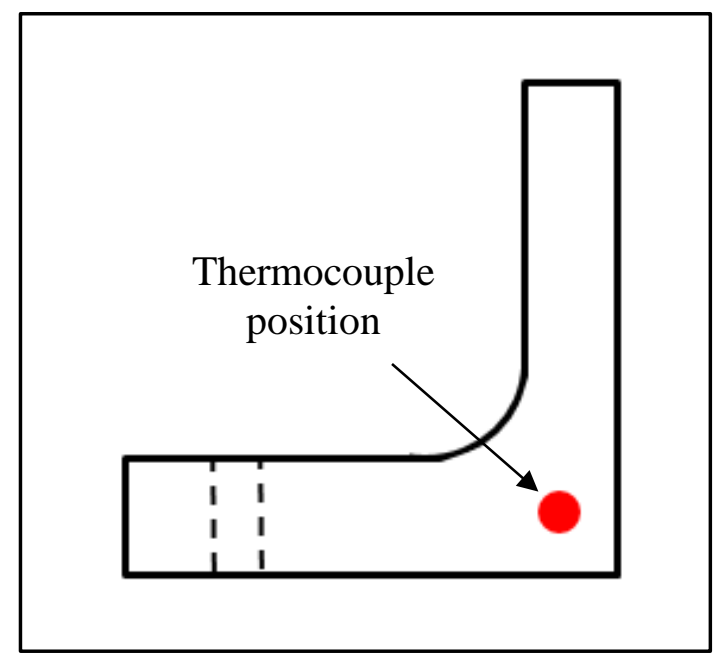

Fig. 17: Thermocouple position in the flange-hub intersection

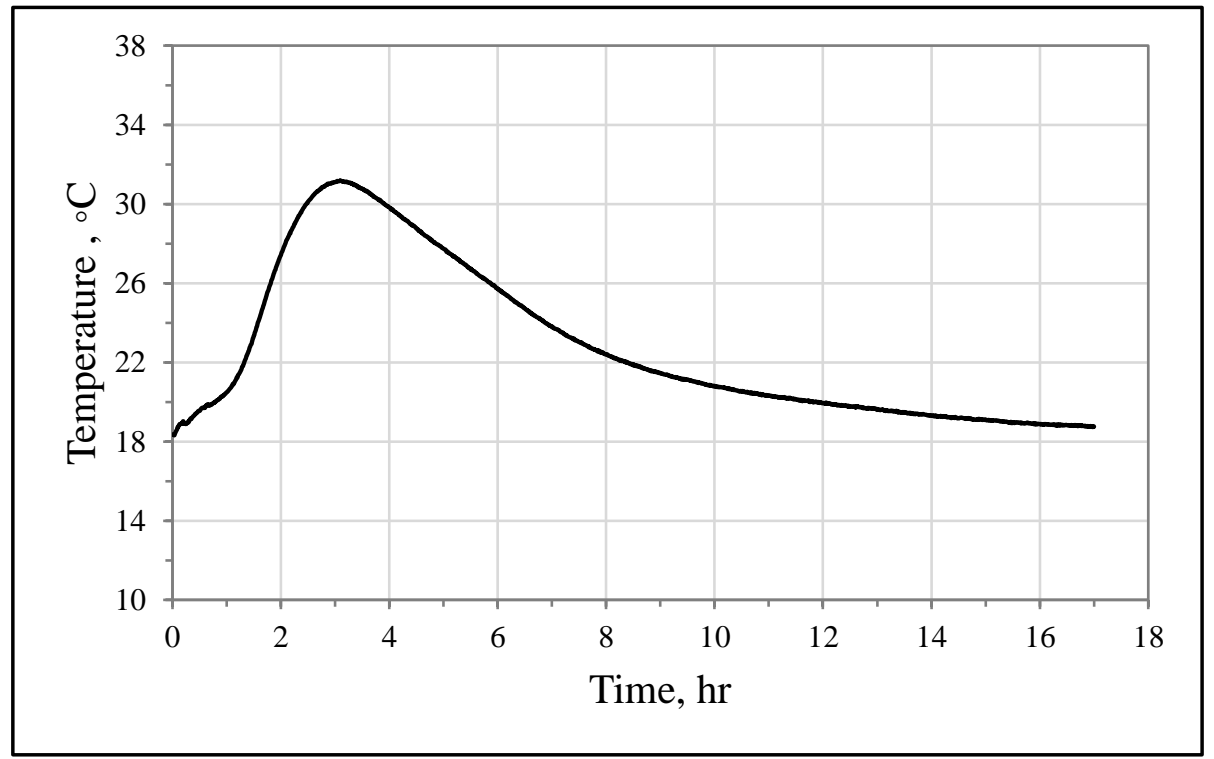

Fig. 18: The temperature variation during the infusion and curing process at the flange-hub intersection 


\subsection{Resin viscosity effect on the void content and dry regions}

The viscosity of the resin has also significant impact on the resin flow and on the curing time. The resin viscosity can be changed by varying the temperature. Therefore, series of experiments were conducted to find out the best infusion temperature that reduces the viscosity and facilitates the flow of the resin through the layers of the fabric. The experiments were carried out using the Brookfield rheometer machine with flat disc and at constant rotation speed for range of temperature $\left(20^{\circ} \mathrm{C}-50^{\circ} \mathrm{C}\right)$. The viscosity has been measured for the polyester resin with zero $\%$ and $1 \%$ catalysts. The resin without catalyst was tested to see the effect of the evaporation on the resin viscosity. The $1 \%$ catalyst was chosen because the manufacturer has recommended the ideal range of the catalyst as 1-2\%. Therefore, it was fixed to $1 \%$ to increase the curing time thereby ensuring good distribution of the resin.

Fig. 19 explains the viscosity variation of the resin with the time for various ranges of temperature. The results show that the viscosity increases from 0.25 Pas to almost 2.2 Pas during the first 30 minutes of the time regardless the temperature. After that, the recorded viscosity has decreased. In reality, it should not decrease but it was happened as the resin film was separated into two layers. One of them has sticked onto the upper plate and the other sticked onto the lower plate of the device. The recorded viscosity after the peak is affected by the friction between the two layers. The temperature has insignificant effect on the viscosity when the resin is used without catalyst.

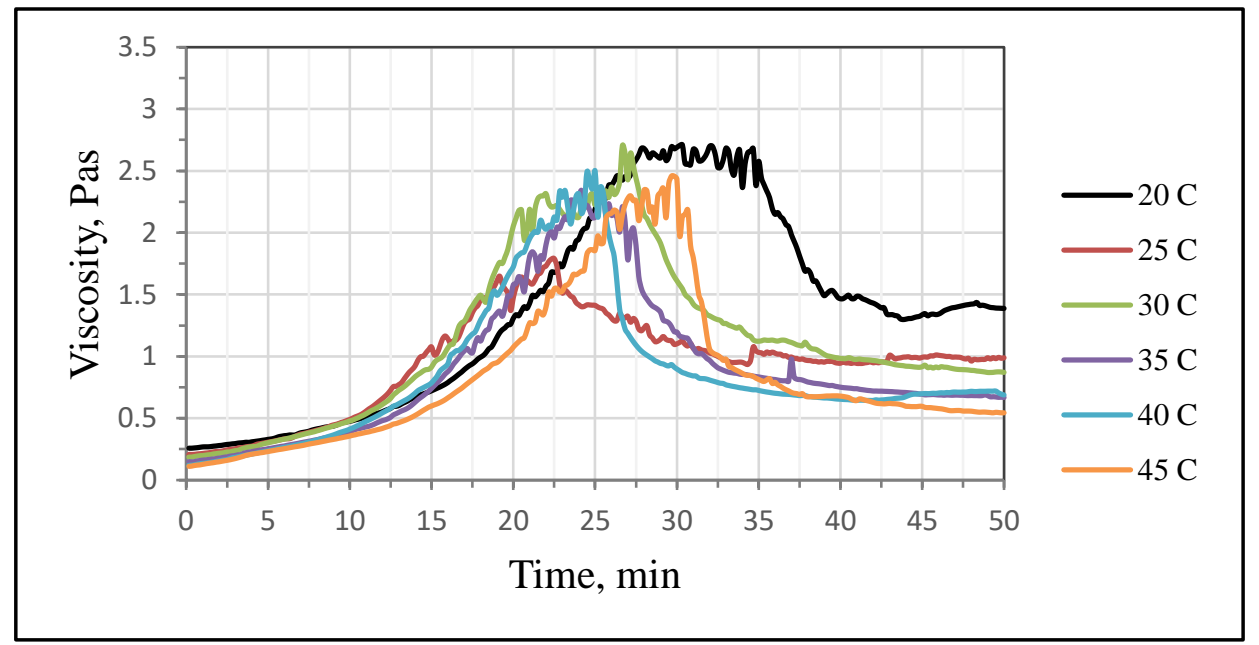

Fig. 19: The variation of the polyester viscosity with the time at different temperature (without catalyst).

Fig. 20 illustrates the variation of the resin viscosity with time for different temperatures (20 to $50^{\circ} \mathrm{C}$ ) for the resin mixed with $1 \%$ of the catalyst. It seems that the temperature has 
significant effect on the resin viscosity. At the high temperatures, 35 to $50^{\circ} \mathrm{C}$, the resin viscosity is increased rapidly and the resin is cured quickly. In addition, the torque has reached the maximum allowable torque of the device and the break has occurred. The time of the break decreases with the increase in the temperature. At the temperatures 25 and $30^{\circ} \mathrm{C}$, the viscosity has increased up to 2.5 Pas during the first 30 minutes but dropped after that. This means the resin film has splitted into two layers. At the room temperature $\left(20^{\circ} \mathrm{C}\right)$, the viscosity has also increased up to 2.5 Pas during the first 35 minutes and reduced gradually after that. The longest period with less viscosity was achieved at the temperature $20^{\circ} \mathrm{C}$. Therefore, this temperature was chosen to infuse the composite flange. This temperature allows the resin to distribute gradually over all regions of the fabric before curing. Furthermore, it lets the trapped air to move and leave the resin. Finally, at the room temperature, it does not require any heating system thus makes the manufacturing process efficient and reduces the costs.

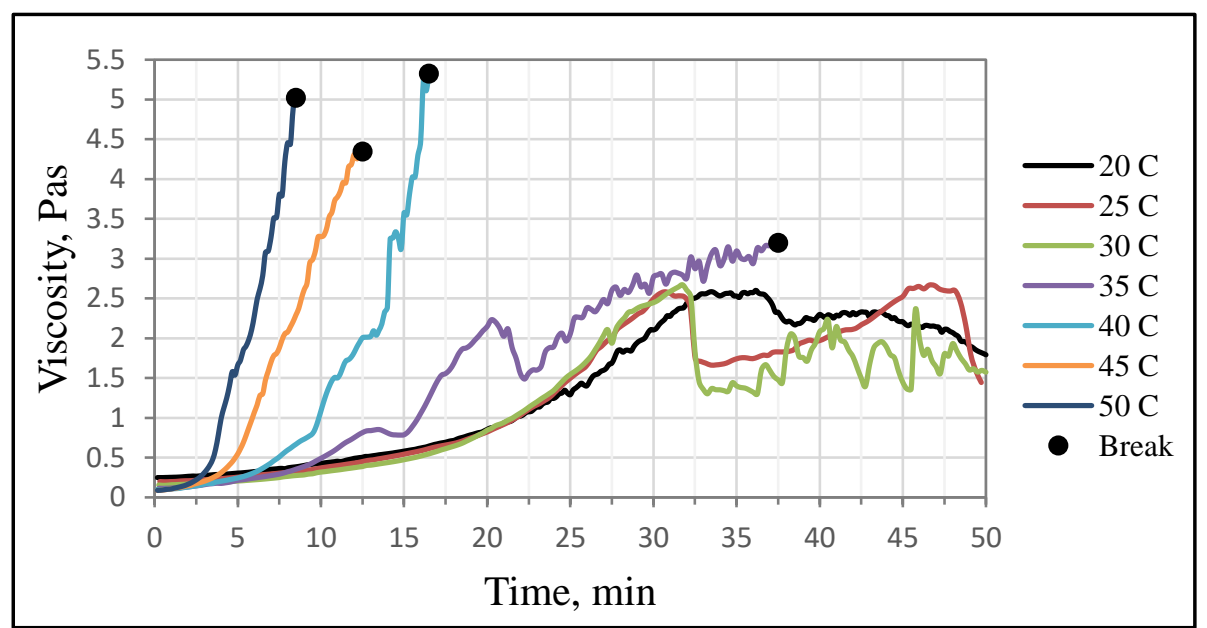

Fig. 20: The variation of the polyester viscosity with the time at different temperature ( $1 \%$ catalyst).

\section{Composite flange drilling}

Drilling the composite flange is one of the main fabrication steps after the curing. The bolts holes are also critical regions in the GFRP flange due to the applied bolt force. So that, the holes' performance has significant effect on the flange performance as most of the maximum stress and strains concentrate at the bolts holes. In addition, it was found that the composite flange with drilled bolts holes performed better, in terms of strength, than those with moulded holes [12]. A number of researchers $[11,13]$ have carried out comparative studies on the drilling of 
the glass fibre reinforced plastics (GFRP), which are manufactured by hand lay-up, using Stub Length drill and Brad \& Spur K10 drill. They found that the Brad \& Spur K10 drill produced less damage on the GFRP composite than the Stub Length.

In this study, a comparative study was conducted using two types of drilling tools with the same cutting conditions for a GFRP plate made of the same fabric and the resin which were used to manufacture the flange. These tools are Erbauer diamond tile drill bit and Brad \& Spur K10 drill, which are illustrated in the Fig. 21. The Brad \& Spur K10 drill was recommended by Davim et al [13]. The results were evaluated in both sides (Inlet and Outlet). As shown in the Fig. 22, the Erbauer diamond tile drill bit has produced a hole with less damage and better than the Brad \& Spur K10 drill in the both sides i.e. the inlet and the outlet of the hole. Therefore, Erbauer diamond tile drill was chosen to drill the holes of the bolts for the composite flange used in this study.

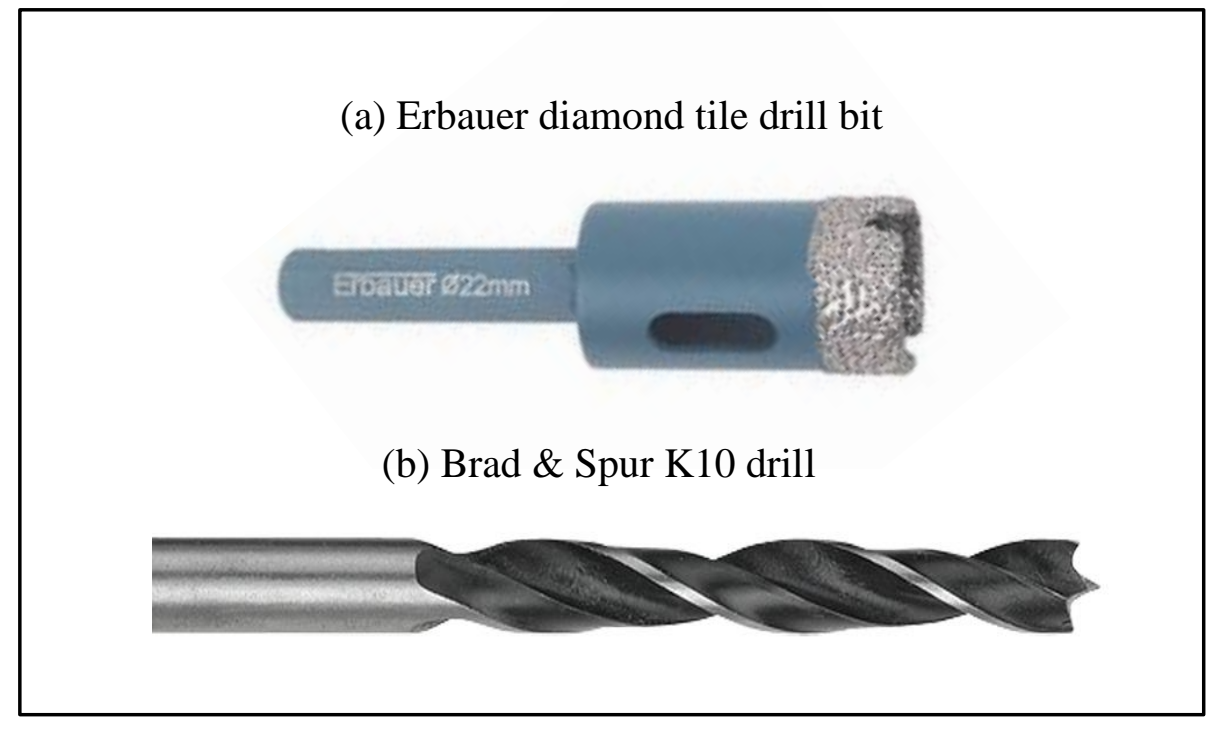

Fig. 21: Drilling tools of the composite.

In addition, other experiments were conducted to find out the best rotation speed for the Erbauer diamond tile drill bit. Same feed rate for all cases and various speeds, e.g. 600, 800, 1200 and $2200 \mathrm{rpm}$ were used to drill the same composite laminate as shown in Fig. 23. The findings show that the best hole in both sides was achieved at the rotation speed of $800 \mathrm{rpm}$ as illustrated in Fig. 24. During drilling, water was used to reduce the heat and to avoid the burning of the composite around the holes. 


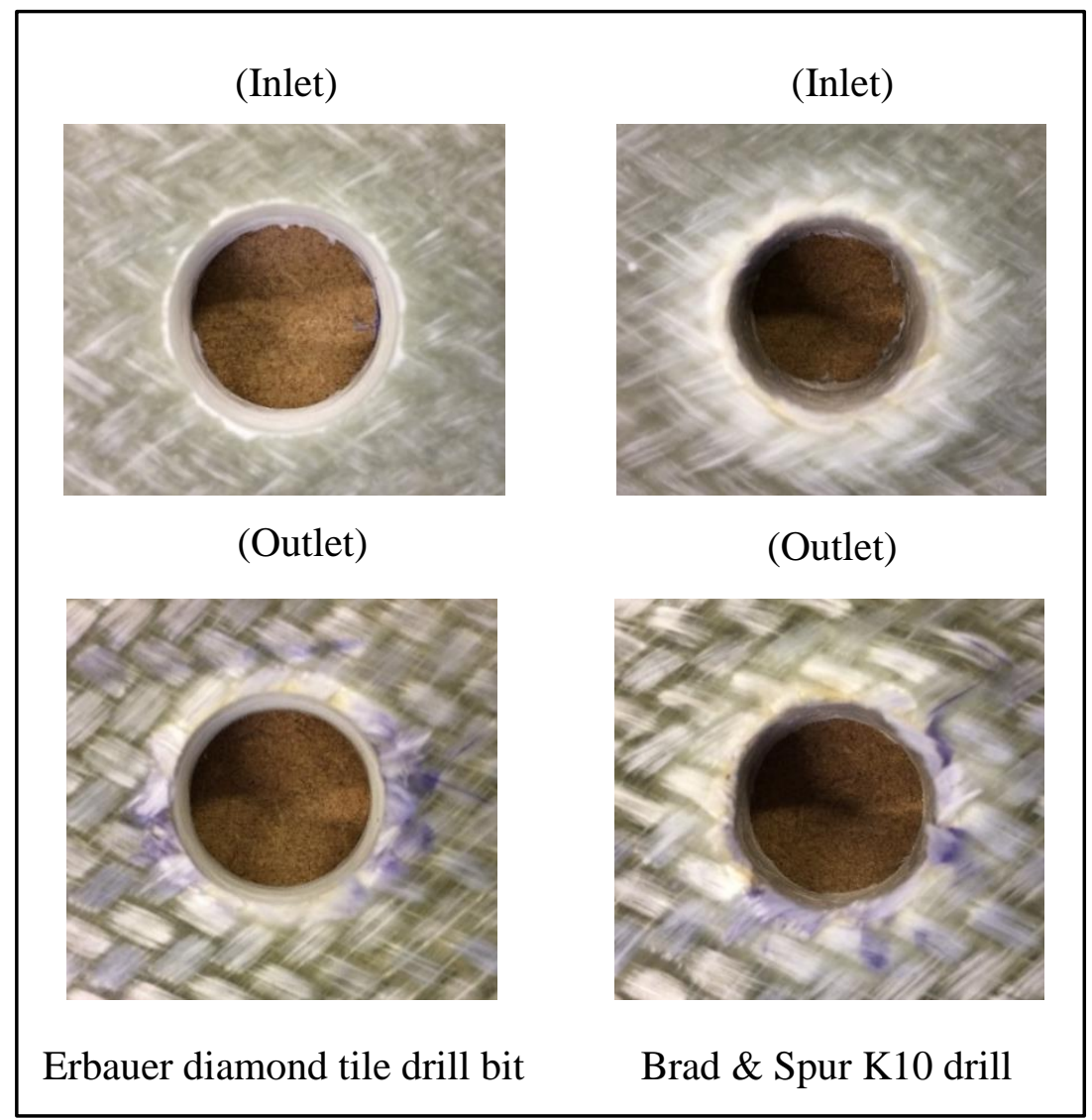

Fig. 22: $22 \mathrm{~mm}$ drilled holes of used tools in the experimental work.

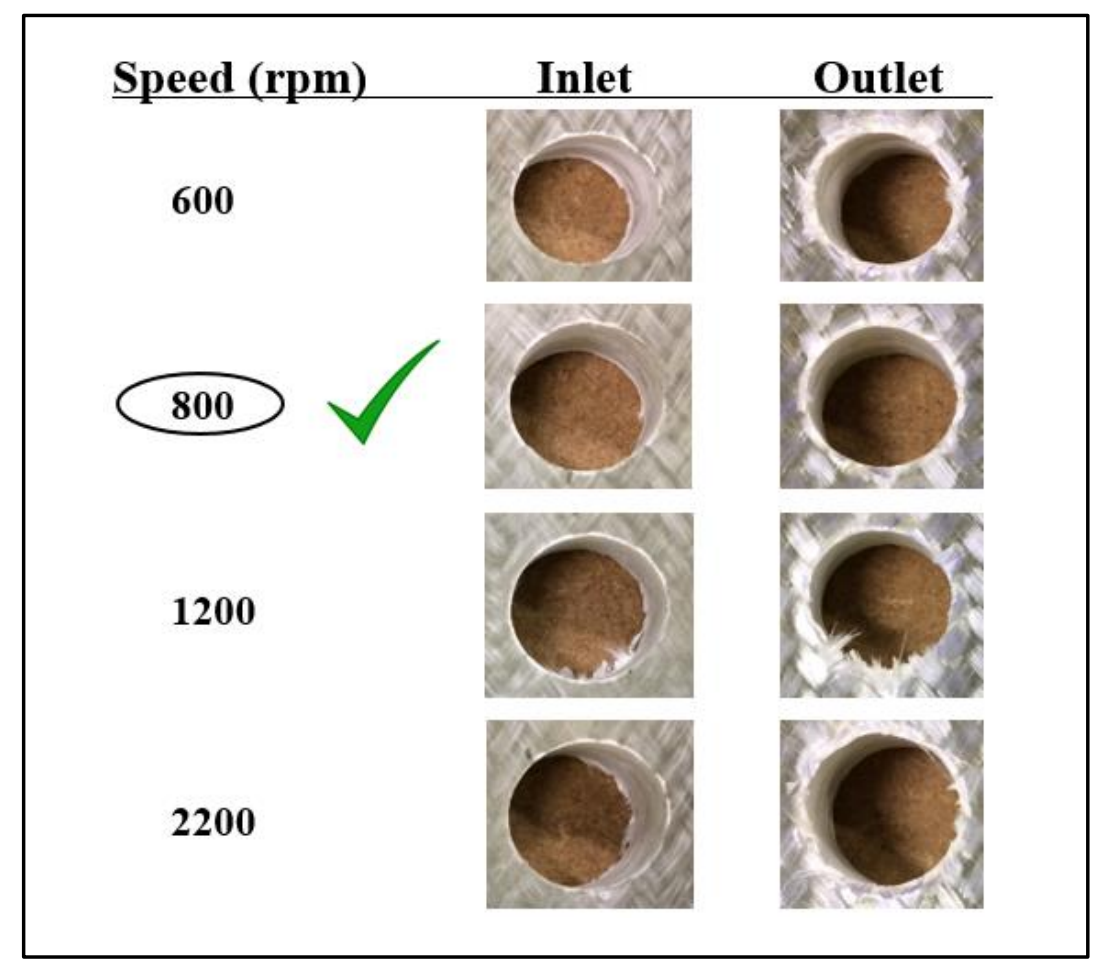

Fig. 23: Drilled holes with different speeds. 


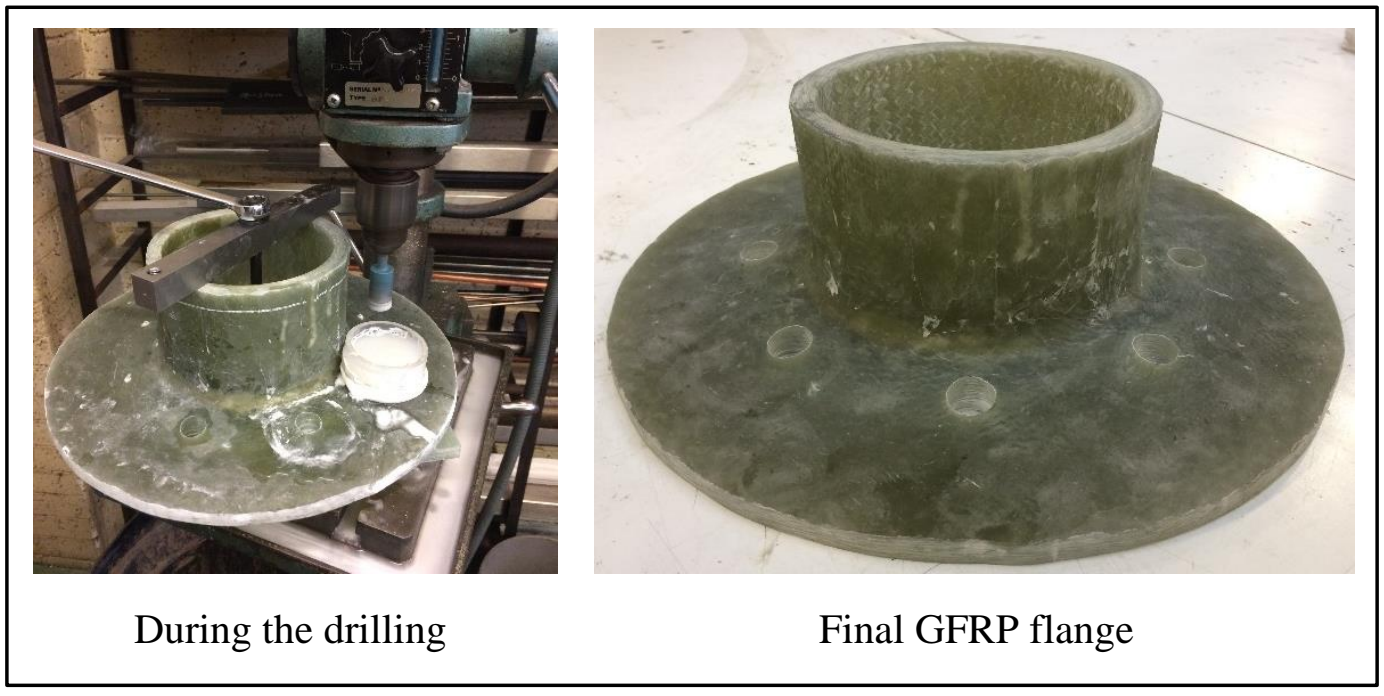

Fig. 24: During the drilled and the final GFRP flange.

\section{Flange-pipe adhesive bonding}

Flange-pipe bonding is important and it was done through many steps. Firstly, the filament winding pipe shown in Fig. 25 was chamfered at its' ends to achieve the requirements of the taper-taper joint between the flange and the pipe. The internal face of the flange was sanded to improve the bonding strength. Epoxy adhesive (PSX $\left.{ }^{\circledR}-60\right)$, which is provided by a commercial company Pipex, was used. The adhesive bonding was reinforced by steel particles and other. Secondly, an axial force was applied using hand puller winch to combine the flange and the pipe. The purpose of using this tool is to apply axial force on the flangepipe joint during the bonding process. This force leads to increase the contact surface area between the flange, the pipe and the adhesive, subsequently maximizes the strength of the adhesively bonded joint. A heating blanket was placed at the inside of the joint. The purpose of the electric heating blanket is to heat up the joint and keep the temperature constant at 130 ${ }^{\circ} \mathrm{C}$, (as recommended by the supplier) during the curing process. Fig. 26 shows the flangepipe joint after the bonding. The other end of the pipe was closed using a Heavy Duty flange, which was installed using the same procedure as the FRP flange. See Fig. 27.b. 


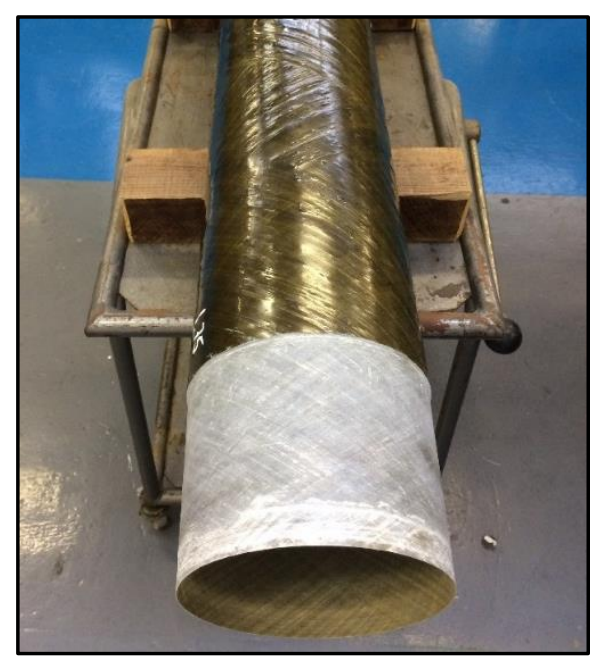

Fig. 25: Chamfering the composite pipe.

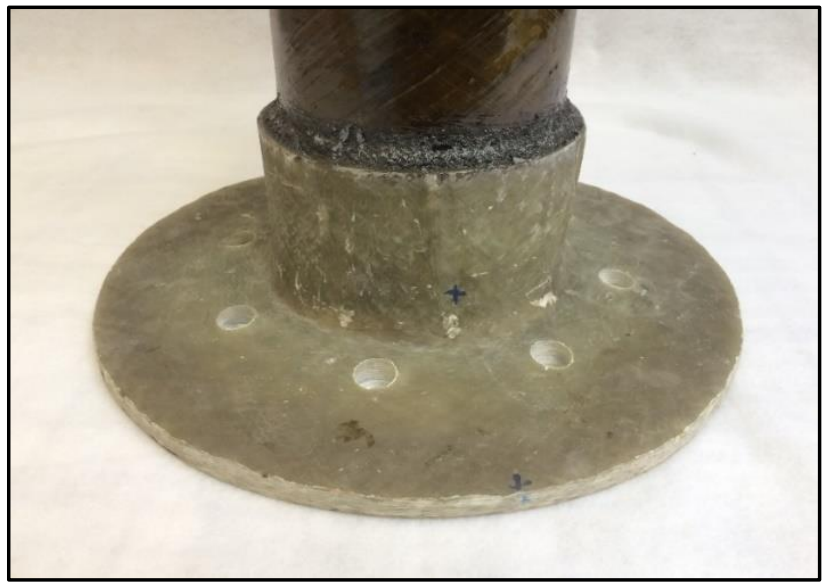

Fig. 26: Flange-Pipe Adhesive bonding

\section{Blind flanges}

Two blind flanges were used to close the ends of the pipe, which were bonded with the fabricated flange in one end and the HD flange in other end of the pipe. The blind flange used for closing the fabricated flange was made of Acrylic material of thickness $50 \mathrm{~mm}$ as shown in Fig. 27.a. The reason for choosing this type of the material is that it is strong and provides clear views for flow observations across the compressed gasket and the leakage propagation. Unfortunately, the leakage propagations have taken place between the gasket and the flange, which cannot be seen. However, the blind flange was made as thick as possible to avoid any deformation on the blind flange. Eight holes, which are identical with holes of the flanges were made to insert the bolts. Initially, water jet cutter (Flow Mach 2 203Ib) was used to make the holes but unfortunately, many cracks around the holes were appeared. As a result, a $\mathrm{CNC}$ machine was used instead of the water jet cutter to make holes for the bolts. 
The blind flange for the other end, which is bonded to the HD flange, was made of mild steel of thickness $25 \mathrm{~mm}$. Eight holes were made for the bolts. In addition, three holes were drilled for the inlet, outlet and the pressure gauge. See Fig. 27.b.

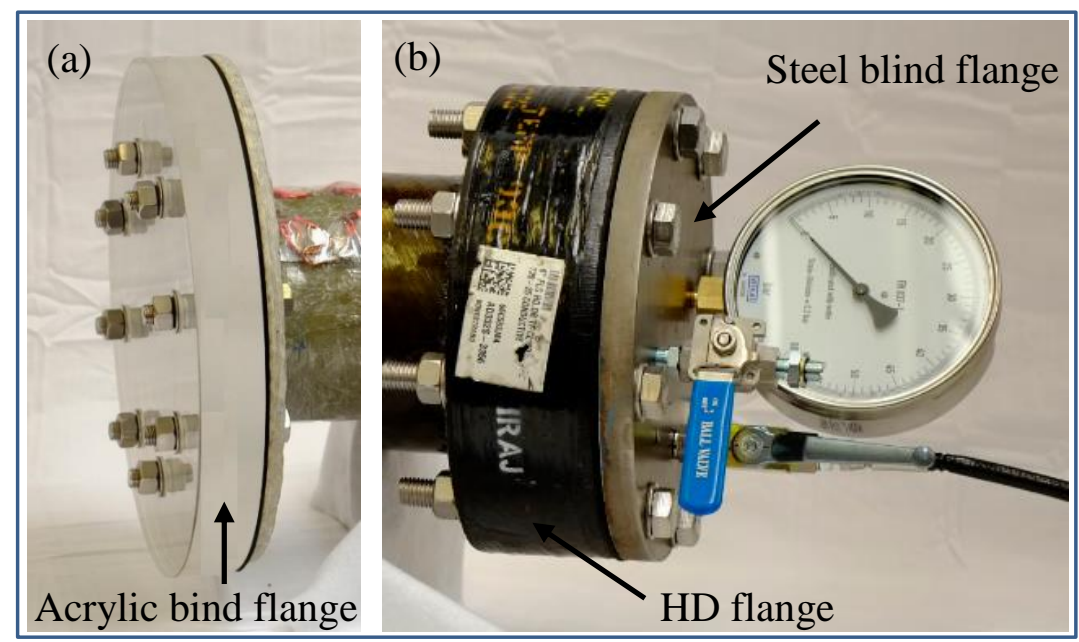

Fig. 27: HD and blind flanges: (a) acrylic blind flange attached to the fabricated flange and (b) HD and steel blind flange attached to the HD flange.

\section{Assembly of the joint components}

After manufacturing all the components of the pressure vessel, the final assembly was carried out as shown in Fig. 28. Many strain gauges were bonded on the GFRP flange body to test the pressure vessel. The pressure vessel has been tested under range of the bolt load and internal pressure using different types of gasket, which are used for oil and gas applications. Some of the results have been published in references [14-18] and the rest will be published in the next articles.

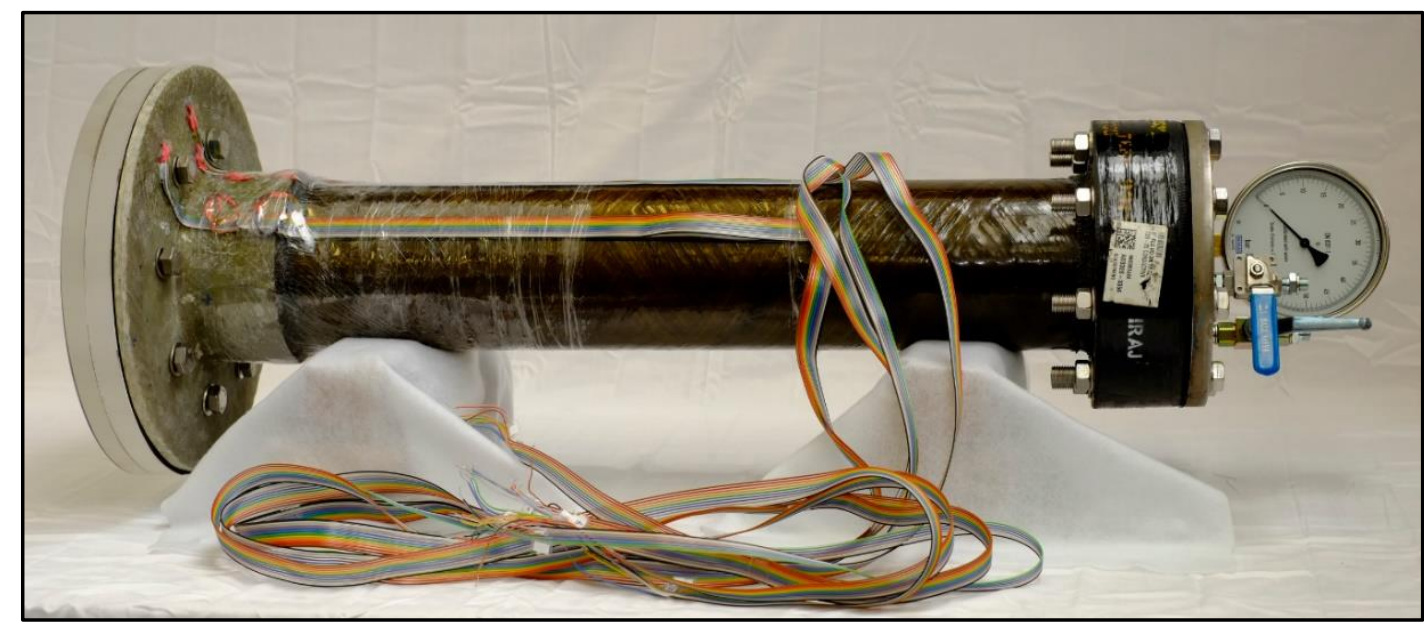

Fig. 28: The pressure vessel. 


\section{Conclusion}

A bolted composite flange made of glass fibre braid reinforced polymer provides good solutions to tackle the most common types of failures found in commercially-available GFRP flanges manufactured by hand lay-up or filament winding processes. Therefore, in this paper, the bolted GFRP flanges were fabricated using a bespoke made mould and vacuum infusion process (bag moulding). The flange is made of $2 \mathrm{D}$ glass fibre braid and polyester resin. In addition, a number of experiments were conducted using different glass mould to solve the faced issues during the fabricating process, to improve the manufacturing process and to obtain a GFRP flange with high quality and strength. Furthermore, to improve the quality of the drilled flange holes, a comparative study was carried out using two types of drill bits. Many different cutting conditions were applied to find the best. Several GFRP flanges were manufactured to improve the manufacturing process and obtain a bolted flange joint made of composites materials with high quality and performance.

\section{Acknowledgement}

This study was a part of my $\mathrm{PhD}$ project, which is titled the design and manufacture of a glass fibre reinforced polymer (GFRP) bolted flange joint for oil and gas applications. This project includes also a numerical study and testing the pressure vessel and the other results will be published in next articles. So that, the author would like to thank supervisors and all technicians, who contributed in the study, in Plymouth University. The authors also would like to gratefully acknowledge the financial supports provided by the HCED in Iraq and thank Pipex for providing some of the materials and technical support.

\section{References}

1. Gemi, L., Tarakçiog ${ }^{` l u}$, N., Akdemir, A., Sßahin, Ö. S., Progressive fatigue failure behavior of glass/epoxy $\left( \pm 75^{\circ}\right)_{2}$ filament-wound pipes under pure internal pressure. Materials \& Design, 2009, 30(10): P. 4293-4298.

2. Lee, C. S., Hwang, W., Park, H. C., Han, K. S., Failure of carbon/epoxy composite tubes under combined axial and torsional loading 1. Experimental results and prediction of biaxial strength by the use of neural networks. Composites Science and Technology, 1999, 59(12): P. 1779-1788..

3. Harvey, W.A. and Kremer, J.S., Design, process development, and fabrication of an all IM 7/977-2 $12 \mathrm{in}$. dia. pressurized fuel line required to operate at -423 F while bolted to an aluminum valve. Evolving technologies for the competitive edge, 1997, P. 839-853.

4. Sun, L., Bolted flanged connections made of fiber reinforced plastic materials. 1995, Concordia University. 
5. Tao, G., Liu, Z., Ly, M.Y., Chen, S., Research on manufacture and test of advanced composite material flang,. Open Mechanical Engineering Journal, 2011. 5: p. 87-96.

6. Whitfield, G.S., Reid, R.G. and Paskaramoorthy, R., Creep and unsymmetrical shrinkage during post-cure of GFRP pipe flanges. 2014.

7. Kurz, H. and Roos, E., Design of floating type bolted flange connections with GRP flanges. International Journal of Pressure Vessels and Piping, 2012, 89: P. 1-8.

8. Fangueiro, R., Nunes, P., Soutinho, F. and Araújo M. de,, Development of fibrous preforms for FRP pipe connections. Composites Science and Technology, 2009, 69(9): P. 1412-1416.

9. ASME Boiler and Pressure Vessel Code, Sextion, X, Fiberglass Reinforced Plastic Pressure Vessels. The American Society of Mechanical Engineers, New York, 2010.

10. Dynaflow research group, GRP Flanges design \& assessment, Rotterdam, 2011.

11. Aljuboury, M., Rizvi M.J., Grove, S. and Cullen, R.., Bolted fibre-reinforced polymer flange joints for pipelines: A review of current practice and future challenges. Proceedings of the Institution of Mechanical Engineers, Part L: Journal of Materials: Design and Applications, 2018.

12. Fiddes, D.E. and Lazarou, J., Press moulded flanges for GRP pipe systems, Composites, 1972, 3(6): P. 254-258.

13. Davim, J.P., Reis, P., and Antonio C.C., Experimental study of drilling glass fiber reinforced plastics (GFRP) manufactured by hand lay-up. Composites Science and Technology, 2004, 64(2): P. 289-297.

14 Aljuboury, M., Rizvi M.J., Grove, S. and Cullen, R.., A numerical investigation of the sealing performance of a bolted GFRP flange joint with rubber gasket, Eleventh International Conference on Composite Science and Technology (ICCST/11), American University of Sharjah, Sharjah, UAE, 2017.

15 Aljuboury, M., Rizvi. Md, Grove S., Cullen, R, ' Manufacturing glass fibre reinforced polymer (GFRP) bolted flange connections by using a vacuum infusion process", Eleventh International Conference on Composite Science and Technology /ICCST/11 April 4-6, 2017, UAE.

16 Aljuboury, M., Rizvi. Md, Grove S., Cullen, R., 'Stress analysis of bolted FRP flange connections under internal pressure,", $5^{\text {th }}$ PRIMaRE Conference, Bristol University 5-6 July 2018, UK.

17 Aljuboury, M., Rizvi. Md, Grove S., Cullen, R., ', Development of manufacturing a bolted flange joint from glass fibre braid reinforced polymer using a vacuum infusion process (VIP) ', International Conference on Manufacturing of Advanced Composites (ICMAC 2018), 10-12 July 2018, Nottingham university, UK.

18. Aljuboury, M., Rizvi. Md, Grove S., Cullen, R., " Bolted flange joint made of glass fibre reinforced polymer (GFRP) for pipelines', The ASME 2018 Pressure Vessels and Piping Conference (PVP2018), 15-20 July 2018,Prague, Czeck Republic. 